\title{
Prevalence of dyslipidaemia and risk factors in Chinese coal miners: a cross-sectional survey study
}

\author{
Ye Fan ${ }^{1 \dagger}$, Jian-Jun Huang ${ }^{2 \dagger}$, Chen-Ming Sun ${ }^{2}$, Nan Qiao ${ }^{3}$, Hai-Xia Zhang ${ }^{4}$, Hui Wang ${ }^{3}$, Ran Tao ${ }^{3}$, Ya-Nan Shen ${ }^{3}$ \\ and Tong Wang ${ }^{3 *}$
}

\begin{abstract}
Background: Although coal miners are susceptible to dyslipidaemia owing to their highly risky and stressful working environment as well as unhealthy lifestyle, very few studies have focused on this issue thus far. Therefore, this study investigated the current epidemiological characteristics of dyslipidaemia among Chinese coal miners.

Methods: Demographic, anthropometric, and biochemical data were gathered from 4341 coal miners in China. Dyslipidaemia was diagnosed based on the serum lipid levels. Univariate and multivariate logistic regression analyses were used to assess the related risk factors for dyslipidaemia.

Results: The average concentrations of total cholesterol (TC), triglyceride (TG), high-density lipoprotein cholesterol (HDL-C), and low-density lipoprotein cholesterol $(\mathrm{LDL}-\mathrm{C})$ were $5.01 \pm 0.93 \mathrm{mmol} / \mathrm{L}, 1.90 \pm 1.72 \mathrm{mmol} / \mathrm{L}, 1.21 \pm 0.35 \mathrm{mmol} / \mathrm{L}$, and $3.15 \pm 0.80 \mathrm{mmol} / \mathrm{L}$, respectively. Additionally, 38.08\% of participants had a high TC level, $25.84 \%$ had a low HDL-C level, 35.08\% had a high LDL-C level, and 40.46\% had a high TG level. The overall prevalence of dyslipidaemia was 68.28\% (95\% Cl: 66.90-69.66\%). Factors associated with dyslipidaemia were age, sex, marital status, monthly family income, type of work, length of service, smoking status, smoking index, drinking status, alcohol consumption per day, elevated fasting glucose, hypertension, obesity and abdominal obesity.
\end{abstract}

Conclusions: Our study's results indicated a very high prevalence of dyslipidaemia among Chinese coal miners and identified various risk factors for dyslipidaemia.

Keywords: Dyslipidaemia, Coal miners, Prevalence, Risk factors

\section{Background}

Cardiovascular disease (CVD) accounts for more than half of all non-communicable diseases and has become the leading cause of death worldwide [1]. Large cohort studies dating back to the Framingham Heart Study have identified cholesterol as a modifiable risk factor, which can be treated with lifestyle and pharmacological interventions [2]. Several clinical trials have demonstrated that treatment for dyslipidaemia is effective for preventing CVD [3, 4], and the treatment of dyslipidaemia can reduce the CVD risk by nearly $30 \%$ over a 5 -year period [5].

\footnotetext{
* Correspondence: tongwangstat@126.com

${ }^{\dagger}$ Equal contributors

${ }^{3}$ Department of Health Statistics, School of Public Health, Shanxi Medical

University, TaiYuan, Shanxi, China

Full list of author information is available at the end of the article
}

Underground coal mining is still one of the most risky occupations globally. Data derived from decennial census and the experience of life insurance companies clearly revealed that death rates for American coal miners are among the highest of any occupational group. When the excess mortality due to respiratory diseases and accidents, which are recognized as hazards related to coal mining, is eliminated, mortality rates for coal miners remain high from 1.4 to 1.7 times the death rates for all workingmen. Excess mortality from other conditions, digestive disorders, certain cancers, and cardiovascular diseases may represent previously unrecognized risks related to coal mining [6]. As non-communicable diseases (NCDs) constitute an increasing portion of the global burden of disease, mining industry employees may be exposed to various factors potentially elevating 
their NCD risk. Underground coal miners work in a limited space and perform various tasks, and they constantly face a wide range of threats from physical factors, such as a high temperature, humidity, noise, vibration, and radiation [7]. Additionally, all these physical factors were related with NCD. Chronic occupational exposure to noise and vibration were associated with the excess mortality risk for acute myocardial infarction $[8,9]$. Dust was also a significant physical factor that workers underground in the mining industry face, as short-term exposure to dust (eg. particulate matter 2.5) increases the risk for hospital admissions for cardiovascular and respiratory diseases [10]. Metabolic risk indicator rates were markedly high and increased significantly from baseline over the 5-year follow-up of a cohort of copper-gold mining company workers, with increased cholesterol, blood pressure, and blood glucose levels and overweight/obesity [11]. A study performed among workers from an opencast iron ore mine in South Goa suggested an association between the occupation in mining with pneumoconiosis and hearing loss, and it showed that the prevalence rates of diabetes, hypertension, dyslipidaemia and polycythemia were $5.1,8.3,37.5$, and $12.7 \%$, respectively [12]. Aldehydes such as acrolein are ubiquitous pollutants present in automobile exhaust, cigarette, wood, and coal smoke. Oral exposure to acrolein could induce or exacerbate dyslipidaemia, as could increase levels of plasma cholesterol and triglycerides, thereby contributing to the risk of cardiovascular disease [13].

Owing to the long exposure to coal dust, coal miners are usually affected by disorders of lipid metabolism [14] and susceptible to CVDs [15]; in addition to their working environment, their lifestyle also plays an important role in their susceptibility to CVDs. Findings from openpit workers indicated a relatively high incidence of hypertension (28\%). The level of arterial hypertension is consistently associated with age, length of occupational experience, and body weight, and high prevalence of cardiovascular risk factors: alcohol consumption, cigarette smoking, family history, consumption of salty foods, and overweight among mining and milling workers [16]. The potential risk factors for dyslipidaemia include genetics, age, diet, smoking, physical activity, and stress [17]. Obviously, adopting a healthy lifestyle with proper medication can control these risk factors and their harmfulness to the body. Therefore, an important public health priority is to prevent dyslipidaemia and its related risk factors. Researchers have shown that the risk of CVD increases as the exposure to coal mine dust and other coal mine risk factors increases $[15,18]$, and an underground work environment in a coal mine is a risk factor for lipid metabolic abnormalities [19]. Therefore, knowledge of the current magnitude of dyslipidaemia in Chinese coal miners is important for enhanced occupational protection measures and prevention and management of CVD, in turn to effectively reduce occupational hazards. However, surveys to determine the burden of dyslipidaemia among Chinese coal miners have not been conducted in the last few years, and available data on the prevalence, types, and related factors of dyslipidaemia in this occupational population are rather limited and outdated. We hypothesized that remarkable changes in the prevalence, type, and risk factors of dyslipidaemia among Chinese coal miners would happen in recent years. Therefore, the purpose of this study was to obtain present data on dyslipidaemia, including its prevalence and risk factors, in coal miners in China.

\section{Methods}

\section{Study population}

Study participants were recruited from the Datong Coal Mine Group, with an estimated 200,000 permanent staff members at 87 coal mines. We obtained the baseline data of all staff from the administrative department of the coal mine group, which included the name, sex, date of birth, and work type to build the sampling frame. Based on these data, study subjects were selected using a two-stage cluster sampling. In the first phase, we randomly sampled 10 coal mines from 87 coal mines as the primary sampling unit. The number of permanent staff members in these sampled coal mines was approximately 38,951. In the second stage, stratified random sampling was applied according to the factors, including the work place (underground front-line, underground auxiliary and surface), age (20-65 years, with groups of 5 -year intervals), and sex (male or female). SAS software, version 9.2 (SAS Institute, Cary, NC, USA) was used to perform Surveyselect procedure. The proportion of the sampling population was $11.2 \%$. Considering no response or other non-compliance issues, we administered a questionnaire to 4400 miners, and 4341 of them returned completed questionnaires from August 1, 2013 to December 30, 2013.

\section{Physical examinations}

The physical examination was performed by trained physicians at the General Hospital of the Datong Coal Mining Group. With the subjects wearing light weight clothes and no shoes, their weight and height were measured using a height-measuring and weightmeasuring instrument. We calculated the body mass index (BMI) by dividing weight in kilograms by height in meters squared. With the subjects standing and breathing normally, their waist circumference (WC) was measured at the umbilicus, and hip circumference was measured around the buttocks. The waist-hip ratio (WHR) was calculated using the following formula: waist circumference $(\mathrm{cm}) /$ hip circumference $(\mathrm{cm})$. 


\section{Blood sample collection and biochemistry analysis}

For all participants, fasting blood samples were collected in the morning after fasting at least $8 \mathrm{~h}$. The lipid panel, including total cholesterol (TC), triglyceride (TG), highdensity lipoprotein cholesterol (HDL-C), and lowdensity lipoprotein cholesterol (LDL-C), serum fasting blood glucose (FBG), along with other routine blood biochemical indexes were determined by routine enzymatic methods on automated modular analysers (Siemens Advia 2400 Chemistry Analyser, Diamond Diagnostic, Holliston, MA, USA) at the General Hospital of the Datong Coal Mining Group.

\section{Definitions of dyslipidaemia, obesity, FBG, and hypertension}

TC, LDL-C, HDL-C, and TG levels were classified based on the 2016 Chinese guideline for the management of dyslipidaemia in adults [20]. Borderline high and high TC was defined as TC levels of $5.2-6.2 \mathrm{mmol} / \mathrm{L}$ $(200-240 \mathrm{mg} / \mathrm{dL})$ and $\geq 6.2 \mathrm{mmol} / \mathrm{L}(\geq 240 \mathrm{mg} / \mathrm{dL})$, respectively, and a TC level $<5.2 \mathrm{mmol} / \mathrm{L}(<200 \mathrm{mg} / \mathrm{dL})$ was defined as acceptable. Low HDL-C was defined as HDL-C levels $<1.0 \mathrm{mmol} / \mathrm{L}(<40 \mathrm{mg} / \mathrm{dL})$. Borderline high and high LDL-C was defined as LDL-C levels of $3.4-4.1 \mathrm{mmol} / \mathrm{L}(130-160 \mathrm{mg} / \mathrm{dL})$ and $\geq 4.1 \mathrm{mmol} / \mathrm{L}$ $(\geq 160 \mathrm{mg} / \mathrm{dL})$, respectively, and LDL-C levels $<3.4 \mathrm{mmol} / \mathrm{L}(130 \mathrm{mg} / \mathrm{dL})$ and $<2.6 \mathrm{mmol} / \mathrm{L}(100 \mathrm{mg} / \mathrm{dL})$ were defined as acceptable and ideal, respectively. Borderline high and high TG was defined as TG levels of 1.7$2.3 \mathrm{mmol} / \mathrm{L} \quad(150-200 \mathrm{mg} / \mathrm{dL})$ and $\geq 2.3 \mathrm{mmol} / \mathrm{L}$ $(\geq 200 \mathrm{mg} / \mathrm{dL})$, respectively, and a TG level $<1.7 \mathrm{mmol} / \mathrm{L}$ $(150 \mathrm{mg} / \mathrm{dL})$ was defined as acceptable.

The Ministry of Health of China defines the following four categories of body weight based on BMI values: underweight, $<18.5 \mathrm{~kg} / \mathrm{m}^{2}$; normal weight, $18.5-23.9 \mathrm{~kg} / \mathrm{m}^{2}$; overweight, $24.0-27.9 \mathrm{~kg} / \mathrm{m}^{2}$; and obesity, $\geq 28.0 \mathrm{~kg} / \mathrm{m}^{2}$ [21]. When the WCs are $\geq 88 \mathrm{~cm}$ for women and $\geq 102 \mathrm{~cm}$ for men, individuals are considered to have "abdominal obesity". In addition, hypso-WHR is defined when the WHRs are $>0.9$ for men and $>0.8$ for women [22].

According to the American Diabetes Association, study participants were categorised into three groups based on FBG levels [23]: normal fasting glucose (NFG; FBG $<5.6 \mathrm{mmol} / \mathrm{L}(100 \mathrm{mg} / \mathrm{dL}))$, impaired fasting glucose (IFG; $5.6 \mathrm{mmol} / \mathrm{L}$ $(100 \mathrm{mg} / \mathrm{dL}) \leq \mathrm{FBG}<7.0 \mathrm{mmol} / \mathrm{L}(126 \mathrm{mg} / \mathrm{dL}))$, and diabetes mellitus (DM; FBG $\geq 7.0 \mathrm{mmol} / \mathrm{L}$ $(126 \mathrm{mg} / \mathrm{dL}))$.

After avoiding exercise and caffeinated beverages for at least one-half hour before measuring blood pressure, the systolic blood pressure (SBP) and diastolic blood pressure (DBP) of the participants were obtained using a mercury sphygmomanometer (GB3053-93 Yuyue, Armamentarium Limited Company, Jiangsu, China). A high blood pressure was defined as a SBP $\geq 140 \mathrm{mmHg}$ and/or DBP $\geq 90 \mathrm{mmHg}$ [24].

\section{Questionnaire}

A survey was conducted by trained investigators after the physical examination. Data were collected by gathering all participants in a conference room along with cardiologists and trained nurses. All participants agreed to participate in a face-to-face interview using a standard questionnaire. Participants' social demographic characteristics (sex, age, etc.), work situation (workplace, work type, etc.), lifestyle and behaviours, medical history, smoking and drinking status, dietary habits, monthly family income, marital status, and educational level were determined by the structured questionnaire.

\section{Statistical analyses}

Data entry was conducted using EpiData 3.0 software (EpiData Association, Odense, Denmark), and to reduce error in generating an electronic data set, we used double data entry. Descriptive analyses of all variables were performed (mean \pm standard deviation for continuous data and frequencies or percentages for categorical variables). Comparisons of continuous variables were made using the unpaired Student's t test. The Pearson's chi-square test was used to evaluate differences in the categorical variables. Furthermore, the prevalence of an abnormal lipid panel according to various characteristics was calculated. Univariate and multivariate logistic regression analyses adjusted for age and sex were used to evaluate the association between blood lipid levels and risk factors, with abnormal TC, TG, HDL-C, and LDL-C levels as dependent variables and demographic characteristics, working characteristics, lifestyles and behaviours, anthropometric characteristics, and biochemical indices as independent variables (entry $=0.05$, removal $=0.10$ ). The association between dyslipidaemia and risk factors was assessed by odds ratios (ORs), and the adjusted ORs were presented with 95\% confidence intervals. To further assess major risk factors for the prevalence of dyslipidaemia and control for potential confounders, we performed stepwise multiple logistic regression analysis to identify the risk factors for each type of dyslipidaemia, adjusted for age and sex. SAS software, version 9.4 (SAS Institute, Cary, NC, USA) was used to perform all statistical analyses. There was a significance difference when $P<0.05$, and all $P$-values were twotailed.

\section{Ethical considerations}

This study was approved by the ethics committee of Shanxi Medical University (ethical application reference: HX201201). All study processes were conducted according to the ethical criteria. After all participants were 
informed of the study's purpose, medical programs, benefits, and non-disclosure agreement of individual information, they signed a written consent.

\section{Results}

\section{Characteristics of the study population}

Overall, 4341 coal miners from 10 coal mines were sampled. The survey population accounted for $2.2 \%$ of the total participants. The mean (standard deviation) age of the subjects was 41.79 (8.64) years, and men accounted for $84.22 \%(3656 / 4341)$ of the population. There were 908 (21.01\%) underground front-line participants, 1497 (34.64\%) underground auxiliary participants, 1118 (25.87\%) ground participants and 798 (18.47\%) office participants. The mean levels of TC, TG, HDL-C, and LDL-C were $5.01 \pm 0.93 \mathrm{mmol} / \mathrm{L}, 1.90 \pm 1.72 \mathrm{mmol} / \mathrm{L}$, $1.21 \pm 0.35 \mathrm{mmol} / \mathrm{L}$, and $3.15 \pm 0.80 \mathrm{mmol} / \mathrm{L}$, respectively. Demographic, clinical, and work characteristics of participants enrolled in this cross-sectional occupational population-based survey according to their dyslipidaemia status are shown in Table 1 . The percentages of men, married participants, drinkers and smokers were all significantly higher in the dyslipidaemia group than in the control group, whereas the percentages of intense physical workers and underground front-line workers were lower $(P<0.001$, except $P<0.05$ for marital status and workplace). The dyslipidaemia group was older; had a higher FBG, SBP, DBP, BMI, waist circumferences, WHR, TC level, TG level, and LDL-C level; and had a lower HDL-C level compared to the non-dyslipidaemia group (all $P<0.001$ ).

\section{Prevalence of dyslipidaemia}

As shown in Tables 1 and 2, 68.28\% (95\% CI: 66.9069.66\%) of Chinese coal miners had at least one type of dyslipidaemia (including borderline high and high TC, LDL-C, and TG levels and a low HDL-C level; men, 71.36\%; women, 51.68\%). Analysis of the dyslipidaemia components showed that $38.08 \%$ of the population had a high TC level, $40.46 \%$ had a high TG level, $35.08 \%$ had an increased LDL-C level, and $25.84 \%$ had an abnormally low HDL-C level. The prevalence rates of borderline high and high TC levels were 27.69 and 10.38\%, respectively; those of borderline high and high LDL-C levels were 23.15 and $11.93 \%$, respectively; that of a low HDL-C level was 25.84\%; and those of borderline high and high TG levels were 16.22 and $24.24 \%$, respectively. The age-specific prevalence of borderline high and high TC, LDL-C, and TG levels increased with increasing age $(P<0.001)$. The prevalences of borderline high and high TC, LDL-C, and TG levels and a low HDL-C level were significantly higher in men than in women, but they were significantly lower in the underground than in the surface workplace and lower in the intense physical work type $(P<0.05)$.

\section{Factors associated with dyslipidaemia}

The prevalence rate of abnormal serum lipid concentrations in accordance with participants' different demographic, work, lifestyle, and behaviour characteristics and the results of univariate logistic analyses of factors associated with dyslipidaemia adjusted by age and sex are presented in Tables 3 and 4, respectively. Notably, the high TC, LDL-C, and TG prevalence significantly increased with advanced age ( $\geq 40$ years), but the low HDL-C prevalence decreased (adjusted ORs $=1.45,1.45$, 1.19 , and 0.85 , respectively; $P<0.05$ ). The ORs for a high LDL-C level, high TG level, and low HDL-C level were lower among women(adjusted ORs $=0.68,0.42$, and 0.29 , respectively; $P<0.001$ ). Only the high prevalence of high TG levels was related to the marital status: married participants had a higher OR of high TG levels than single participants (adjusted $\mathrm{OR}=1.63 ; P<0.001$ ). Subjects with a high family income were more likely to have lower ORs of high TC level ( $>6000$ yuan: adjusted $\mathrm{OR}=0.79 ; P<0.05)$ and low HDL-C level $(4000-6000$ yuan: adjusted $\mathrm{OR}=0.66 ; P<0.001$ ).

Participants who did light physical and mental work were more likely to have higher ORs of high LDL-C levels (adjusted ORs $=1.29,1.48$, respectively; $P<0.05$ ), high TG levels (adjusted ORs $=1.60,1.70$, respectively; $P<0.001$ ) and low HDL-C levels (adjusted ORs $=1.68$, 1.73 , respectively; $P<0.001$ ) than those who did intense physical labour. Further, compared to the underground front-line work group, the surface work place group were more inclined to suffer from high TC (ground: adjusted OR $=1.41 ; P<0.001$ ), high LDL-C (ground: adjusted $\mathrm{OR}=1.49 ; P<0.001$; office: adjusted $\mathrm{OR}=1.49$; $P<0.001$ ), high TG (adjusted ORs for underground auxiliary, ground and office $=1.49,1.50,1.73$, respectively; $P<0.001$ ) and low HDL-C (adjusted ORs for underground auxiliary, ground and office $=1.29,1.76,1.68$, respectively; $P<0.05)$. Additionally, having an extended length of service ( $>10$ years of service) increased the tendency of high TC (adjusted OR $=1.87 ; P<0.05$ ) and high LDL-C levels (adjusted OR $=1.98 ; P<0.05$ ).

Cigarette smoking and the prevalence of high TC and high LDL-C levels showed a positively relationship (adjusted ORs $=1.28$ and 1.24, respectively; $P<0.05$ ). In addition, participants with a bigger smoking index had a greater prevalence of high TC $(150 \sim$ and 450 : adjusted ORs $=1.41$ and 1.35 , respectively; $P<0.05)$ and high LDL-C levels $(150 \sim$ and 450 : adjusted ORs $=1.34$ and 1.37 , respectively; $P<0.05$ ). The prevalence of high TC and high TG levels was higher among current drinkers than non-drinkers, but the trend was opposite for low HDL-C levels (adjusted ORs $=1.39,1.33$, and 0.70, respectively; $P<0.001$ ). The daily alcohol consumption was positively associated with a high prevalence rate of elevated TC levels $(25 \sim \mathrm{g} / \mathrm{d}, 50 \sim \mathrm{g} / \mathrm{d}$ and $75 \sim \mathrm{g} / \mathrm{d}$ : 


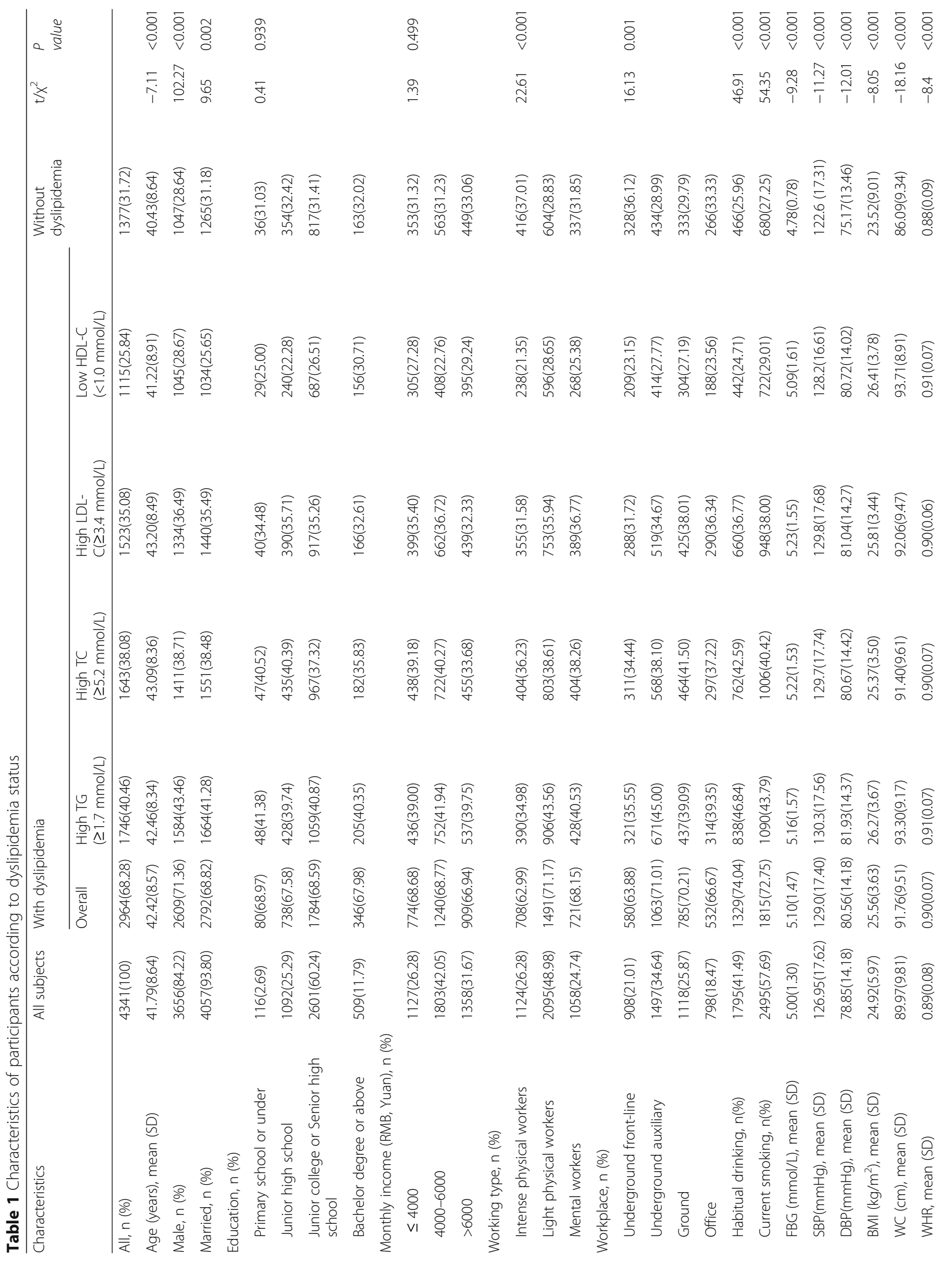




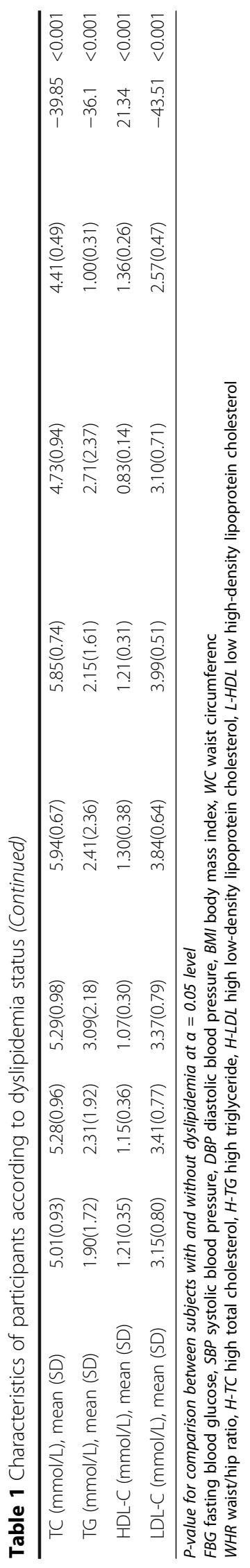




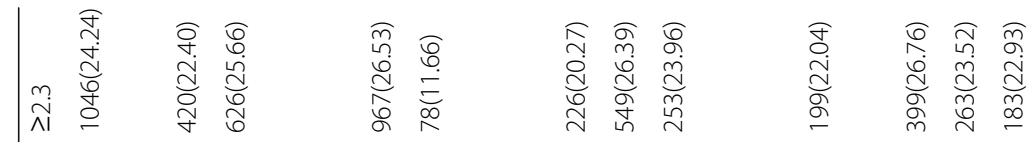

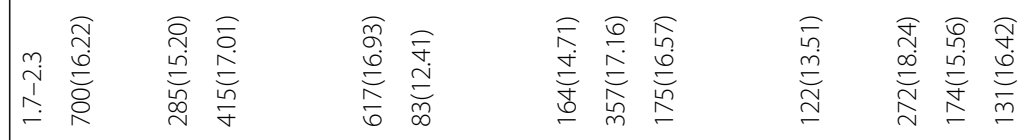

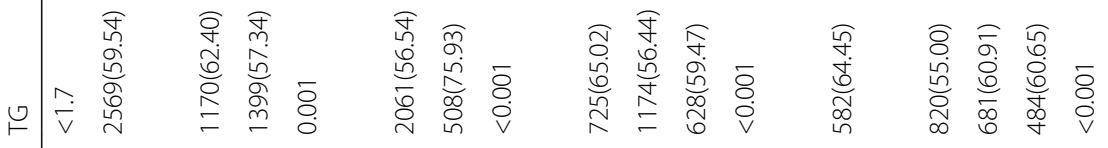

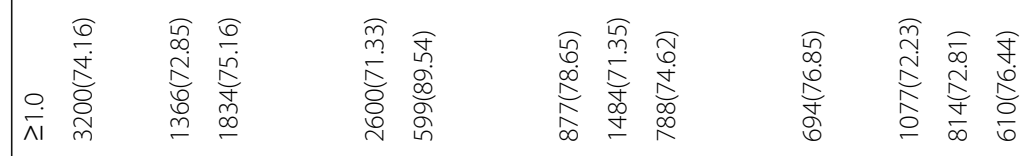

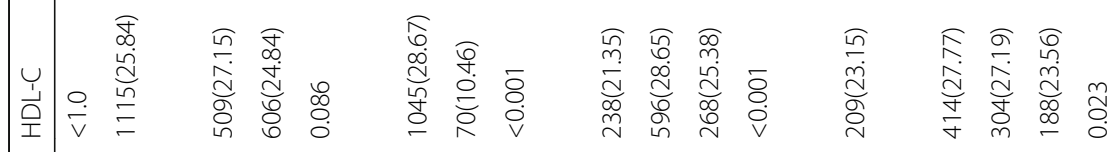

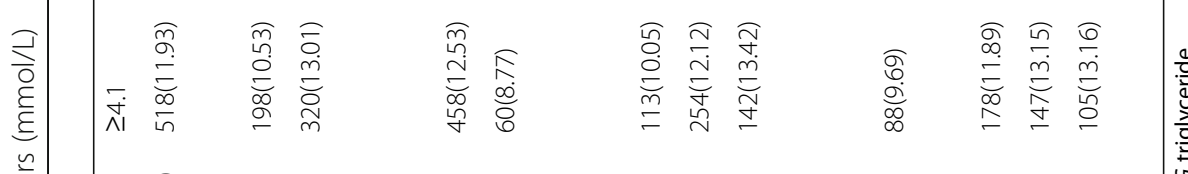

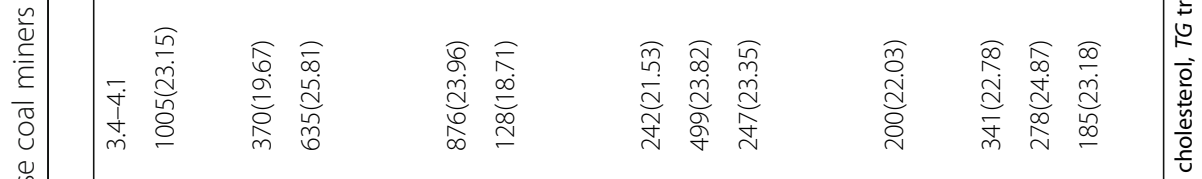

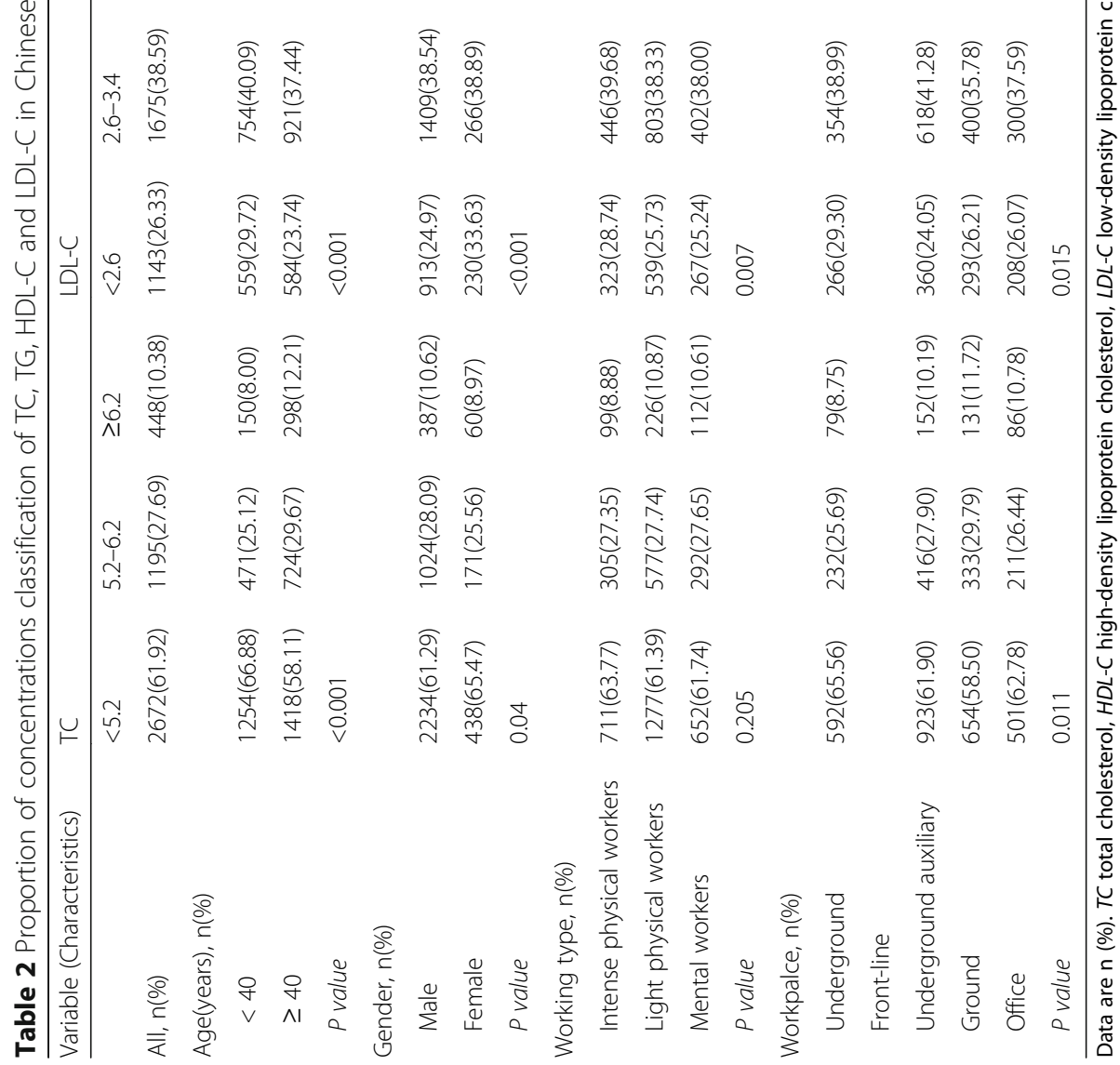




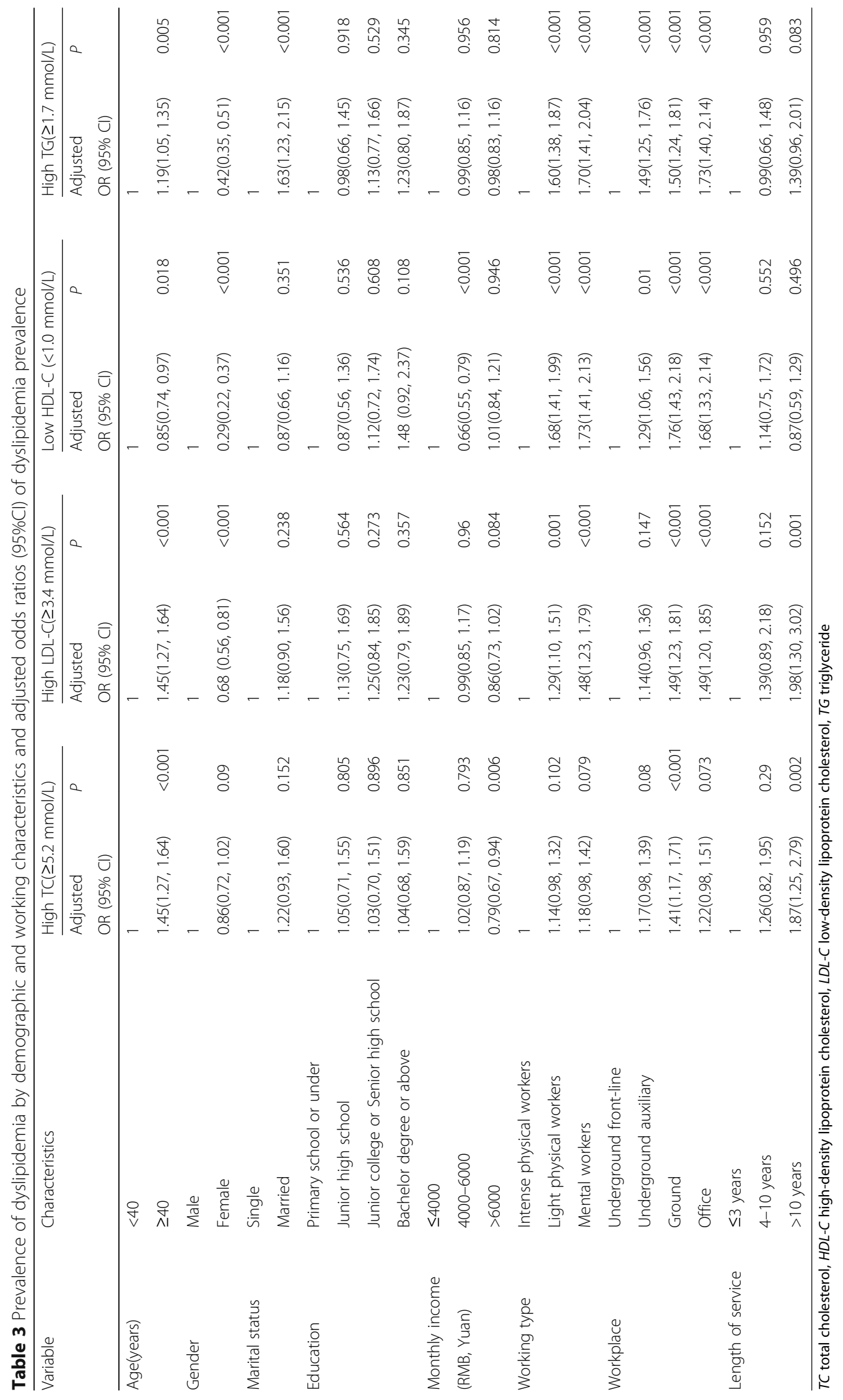




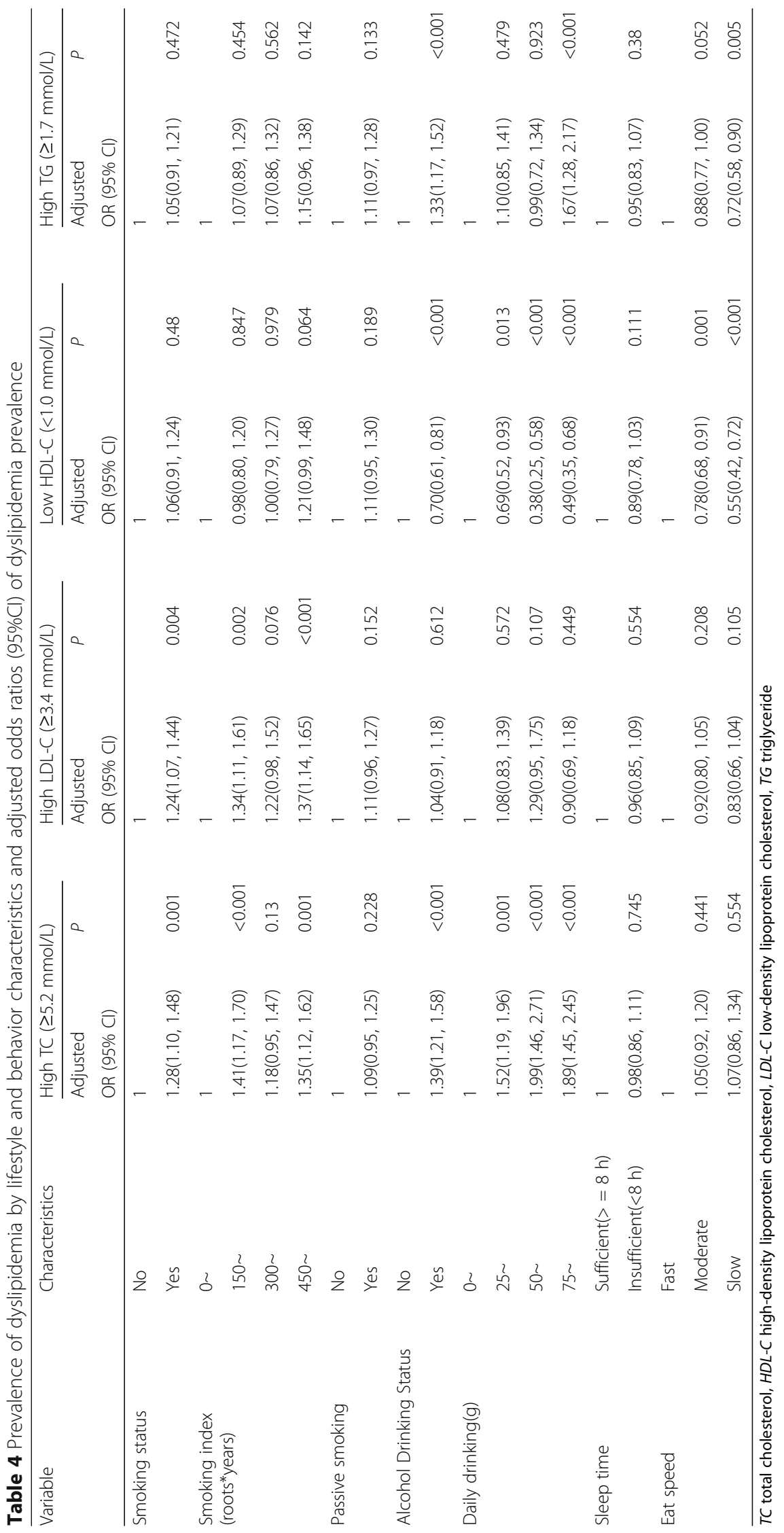


adjusted ORs $=1.52,1.99$, and 1.89, respectively; $P<0.05)$ and elevated TG levels $(75 \sim \mathrm{g} / \mathrm{d}$ : adjusted $\mathrm{OR}=1.67 ; P<0.001)$, but it was inversely related to the prevalence of low HDL-C levels $(25 \sim \mathrm{g} / \mathrm{d}, 50 \sim \mathrm{g} / \mathrm{d}$, and $75 \sim$ g/d: adjusted ORs $=0.69,0.38$ and 0.49, respectively; $P<0.05)$. Participants with a slower eating speed had lower ORs of low HDL-C levels (moderate and slow eating speed: adjusted $\mathrm{ORs}=0.78$ and 0.55 , respectively; $P<0.05$ ) and elevated TG levels (slow eating speed: adjusted $\mathrm{OR}=0.72 ; P<0.05)$ than participants who had a faster eating speed. Furthermore, there was no significant association of the prevalence of any kind of dyslipidaemia with education level, passive smoking, and sleep time.

Results of univariate logistic analyses of the anthropometric and biochemistry indices associated with dyslipidaemia, adjusted by age and sex, are shown in Table 5 . Participants who had elevated fasting glucose levels were more likely to have a higher prevalence rate of high TC levels (IFG: adjusted $\mathrm{OR}=1.55, \mathrm{DM}$ : adjusted $\mathrm{OR}=2.32$; $P<0.001$ ), high LDL-C levels (IFG: adjusted OR $=1.40$, DM: adjusted OR $=2.06 ; P<0.05$ ), high TG levels (IFG: adjusted $\mathrm{OR}=1.80$, DM: adjusted $\mathrm{OR}=3.28 ; P<0.001$ ) and low HDL-C levels (DM: adjusted OR = 1.96; $P<0.001)$. Subjects with hypertension had an increased tendency of high TC levels (SBP: adjusted OR $=1.38$, DBP: adjusted OR $=1.45 ; P<0.001)$, high LDL-C levels (SBP: adjusted OR $=1.36, \mathrm{DBP}$ : adjusted $\mathrm{OR}=1.47$; $P<0.001)$, high TG levels (SBP: adjusted OR $=1.65$, DBP: adjusted OR $=1.99 ; P<0.001)$, and low HDL-C levels (DBP: adjusted OR $=1.24 ; P<0.05$ ). Additionally, participants with a large body size had a greater prevalence of high TC levels (overweight: adjusted $\mathrm{OR}=1.50$, obese: adjusted $\mathrm{OR}=1.73 ; P<0.001)$, high LDL-C levels (overweight: adjusted $\mathrm{OR}=1.86$, obese: adjusted $\mathrm{OR}=2.56 ; P<0.001$ ), low HDL-C levels (overweight: adjusted $\mathrm{OR}=2.09$, obese: adjusted $\mathrm{OR}=3.77$; $P<0.001$ ), and high TG levels (overweight: adjusted $\mathrm{OR}=2.92$, obese: adjusted $\mathrm{OR}=5.16 ; P<0.001)$. Participants with central obesity tended to suffer high TC levels (large waist: adjusted OR $=1.30$, hypso-WHR: adjusted OR $=1.28 ; P<0.05$ ), high LDL-C levels (large waist: adjusted $\mathrm{OR}=1.54$, hypso-WHR: adjusted $\mathrm{OR}=1.41 ; P<0.001$ ), low HDL-C levels (large waist: adjusted $\mathrm{OR}=2.48$, hypso-WHR: adjusted OR = 1.74; $P<0.001$ ), and high TG levels (large waist: adjusted $\mathrm{OR}=2.86$, hypso-WHR: adjusted $\mathrm{OR}=1.95 ; P<0.001)$.

\section{Results of multivariable logistic regression analysis of dyslipidaemia}

Data in Table 6 suggest that the presence of high TC levels was still positively associated with an extended length of service ( $>10$ years: adjusted $\mathrm{OR}=1.70$; $P<0.05$ ), smoking status (adjusted $\mathrm{OR}=1.25 ; P<0.05$ ), increased alcohol consumption $(25 \sim \mathrm{g} / \mathrm{d}, 50 \sim \mathrm{g} / \mathrm{d}$ and $75 \sim$ g/d: adjusted ORs $=1.53,1.81$ and 1.73, respectively; $P<0.05$ ), elevated fasting glucose (IFG: adjusted $\mathrm{OR}=1.41 ; P<0.05 ;$ DM: adjusted OR = 1.99; $P<0.001$ ), hypertension (DBP: adjusted OR = 1.23; $P<0.05$ ), and bigger body size (overweight: adjusted $\mathrm{OR}=1.43$, obese: adjusted $\mathrm{OR}=1.66 ; P<0.001)$, but it was inversely related to the monthly family income (>6000 yuan: adjusted OR $=0.76 ; P<0.05$ ). Participants who engaged in mental labour (adjusted OR = 1.35; $P<0.05)$, had an extended length of service $(>10$ years: adjusted $\mathrm{OR}=1.77 ; P<0.05)$, higher smoking index (150 , $300 \sim$ and 450 : adjusted ORs = 1.39, 1.28, and 1.42, respectively; $P<0.05$ ), elevated fasting glucose (DM: adjusted OR $=1.61 ; P<0.05)$, hypertension (DBP: adjusted $\mathrm{OR}=1.30 ; P<0.05$ ), or bigger body size (overweight: adjusted OR $=1.77$, obese: adjusted OR $=2.35$; $P<0.001)$ had an increased tendency of a high LDL-C level. Table 6 also illustrates that participants who were married (adjusted OR $=1.43 ; P<0.05$ ), engaged in light physical or mental labour (adjusted ORs $=1.51$ and 1.58, respectively; $P<0.001$ ), drinking (adjusted $\mathrm{OR}=1.24$; $P<0.05)$, had increased alcohol consumption $(75 \sim \mathrm{g} / \mathrm{d}$ : adjusted $\mathrm{OR}=1.37 ; P<0.05)$, elevated fasting glucose (IFG: adjusted OR $=1.46 ;$ DM: adjusted OR $=2.32$; $P<0.001$ ), hypertension (DBP: adjusted OR = 1.58; $P<0.001$ ), bigger body size (overweight: adjusted $\mathrm{OR}=2.61$, obese: adjusted $\mathrm{OR}=3.55 ; P<0.001)$, or abdominal obesity (large waist: adjusted OR $=1.41$, hypsoWHR: adjusted OR $=1.25 ; P<0.05)$ were more inclined to have high TG levels than those without these conditions; however, the trend was opposite for women (adjusted $\mathrm{OR}=0.41 ; P<0.001)$. Performing light physical or mental labour (adjusted ORs $=1.61$ and 1.52, respectively; $P<0.001$ ), having an elevated fasting glucose (DM: adjusted $\mathrm{OR}=1.45 ; P<0.05$ ), bigger body size (overweight: adjusted $\mathrm{OR}=1.98$, obese: adjusted $\mathrm{OR}=2.95$; $P<0.001$ ), or abdominal obesity (large waist: adjusted $\mathrm{OR}=1.45$, hypso-WHR: adjusted $\mathrm{OR}=1.21 ; P<0.05)$ had an increased risk for low HDL-C; however, having an increased age (adjusted OR $=0.80 ; P<0.05$ ), female sex (adjusted OR $=0.18 ; P<0.001$ ), higher monthly family income (4000-6000 yuan: adjusted OR = 0.67; $P<0.001$ ), drinking status (adjusted $\mathrm{OR}=0.79$; $P<0.05)$, or increased alcohol consumption $(50 \sim \mathrm{g} / \mathrm{d}$ and $75 \sim$ g/d: adjusted ORs $=0.36$ and 0.58 , respectively; $P<0.05)$ had the reverse tendency.

\section{Discussion}

In accordance with a World Health Organization report, of the 56 million deaths worldwide in 2012, 38 million deaths (about 68\%) were caused by non-infectious diseases, which have become a severe worldwide public health burden $[25,26]$. Generally, CVD is the most 


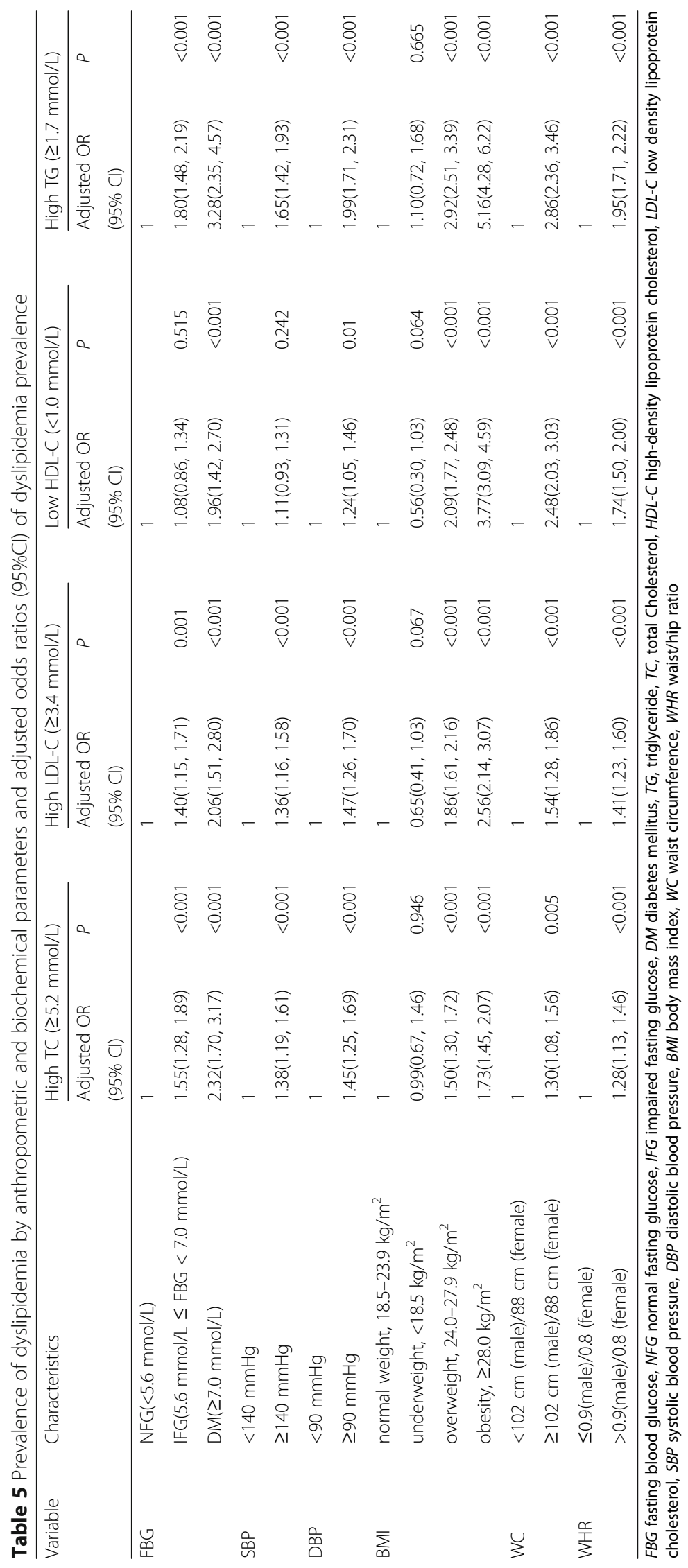




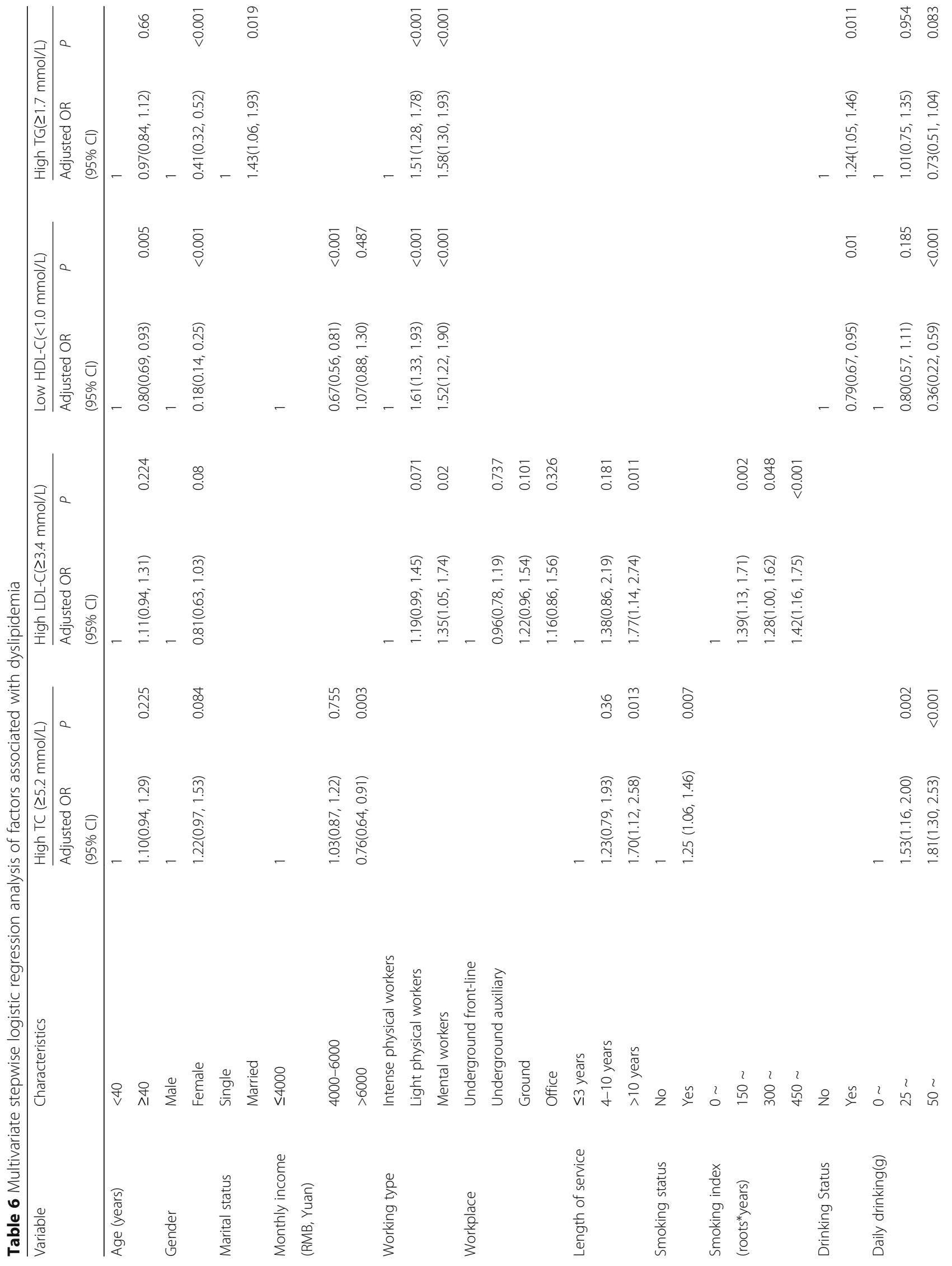


Fan et al. Lipids in Health and Disease (2017) 16:161

Page 13 of 17

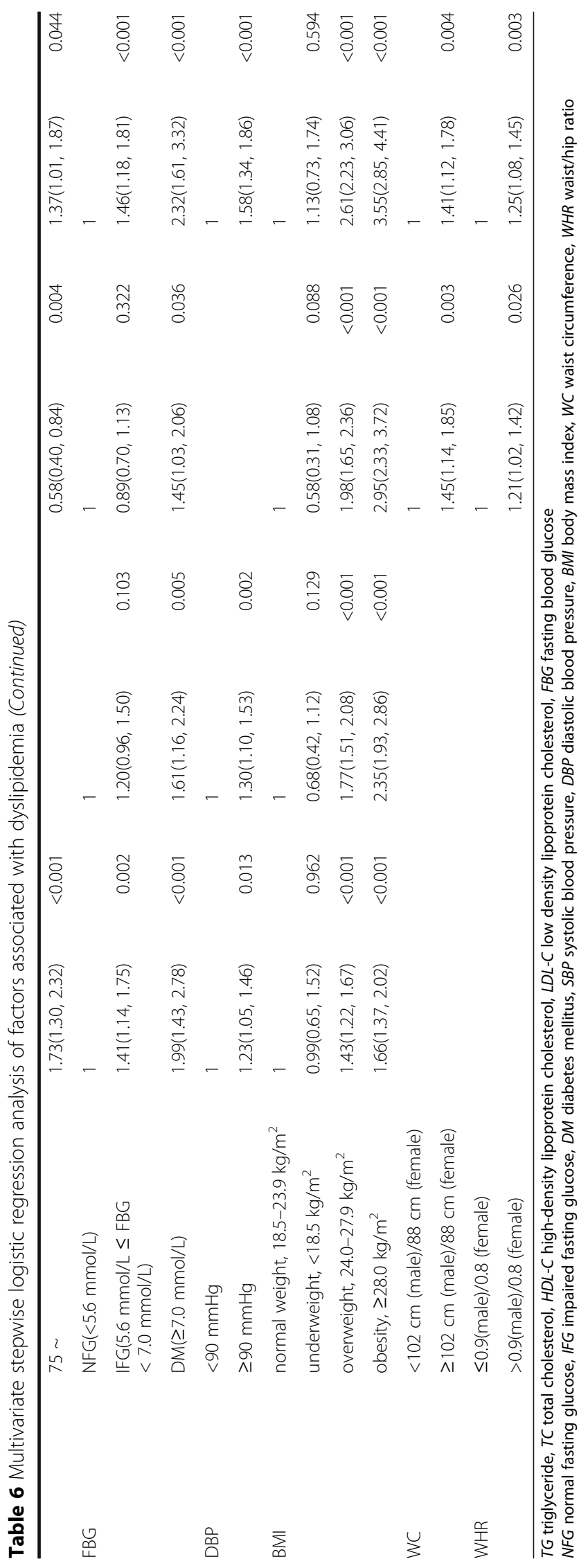


outstanding condition globally, and dyslipidaemia is an important public health problem, with an increasing prevalence worldwide. As dyslipidaemia is one of the most crucial independent reversible risk factors for CVDs, preventive measures targeting the popular with dyslipidaemia can reduce the morbidity and mortality of CVDs [27]. To effectively prevent CVDs, lifestyle modifications, policy changes, and pharmacotherapy are required. The current study is one of the largest scale occupational, population-based studies on dyslipidaemia that comprehensively assessed the prevalence of dyslipidaemia and the associated risk factors of dyslipidaemia in coal miners in China.

The average serum TC, LDL-C, and TG levels have increased quickly in China [28-30]. Findings from the 2002 Chinese National Nutrition and Health Survey (CNHS) $[28,31]$ demonstrated that the respective mean levels of TC, LDL-C, and TG were $3.81 \mathrm{mmol} / \mathrm{L}$, $2.21 \mathrm{mmol} / \mathrm{L}$, and $1.10 \mathrm{mmol} / \mathrm{L}$. The China National Diabetes and Metabolic Disorders Study demonstrated that the respective mean levels of TC, LDL-C, and TG were $4.72 \mathrm{mmol} / \mathrm{L}, 2.68 \mathrm{mmol} / \mathrm{L}$ and $1.57 \mathrm{mmol} / \mathrm{L}$ [32]; the corresponding average levels observed in the current study were higher: $5.01 \mathrm{mmol} / \mathrm{L}, 3.15 \mathrm{mmol} / \mathrm{L}$, and $1.90 \mathrm{mmol} / \mathrm{L}$, respectively. Furthermore, in our study, the average level of serum HDL-C was somewhat lower $(1.21 \mathrm{mmol} / \mathrm{L})$ than that $(1.30 \mathrm{mmol} / \mathrm{L})$ reported in the two aforementioned studies [28, 31, 32].

Our current study's findings indicated that $68.28 \%$ of Chinese coal miners (men, 71.36\%; women, 51.68\%) had at least one type of dyslipidaemia. This value is higher than that reported by the 2002 CNHS $(18.6 \%)$ [28] and by recent studies on Chinese adults [27, 33, 34]. Our findings showed that the prevalence of dyslipidaemia is high in coal miners. In line with the results of previous studies [27, 33, 34], which found that the main types of dyslipidaemia in China are high TG levels, our study showed that the major contributor of dyslipidaemia was high TG levels $(40.46 \%)$. In the past 20 years, the most prominent change in the concentrations of serum lipids in the people of Beijing and Guangzhou in China was an increase in the TG levels, possibly as a result of the increase in carbohydrates and fats in their diet [35-37], whereas the most common lipid disorder in Western countries was high TC levels [38]. Furthermore, China has a low mortality due to coronary heart disease, and the relationship between a low serum TC level and low fat and cholesterol dietary intake was identified as the main cause of this finding [39]. However, with economic growth and westernized lifestyle, especially dietary patterns, the prevalence of high TC levels increased in China [27, 34], and the prevalence of a high TC level (38.08\%) found in this study was significantly higher than the average Chinese national level [33]. Projected trends in the increased TC level would lead to an increase of approximately 9.2 million cardiovascular events from 2010 to 2030 [40]. The association between regional disparities in the type of dyslipidaemia and lifestyle, diet, and other factors requires further investigation. Our findings of the high prevalence of dyslipidaemia in coal miners highlight crucial public health implications what could explain why this population is susceptible to CVDs [15].

In addition to the prevalence of dyslipidaemia, our study identified the potential risk factors for each type of dyslipidaemia: type of work, hypertension, BMI, WC, etc. Previous studies have reported an association between age and dyslipidaemia [27, 29, 38, 41]. The mechanisms underlying the role of age on serum lipid panel results may be hereditary characteristics, degenerative processes, weight gain, and gradual development of insulin resistance [38]. In the current study, univariate logistic regression analysis demonstrated that the prevalence of high TC levels, LDL-C levels, and TG levels significantly increased with advanced age ( $\geq 40$ years); however, the prevalence of low HDL-C levels decreased, which was in accordance with the results of another previous study [42]. However, multivariate analysis only confirmed the relationship of age and low HDL-C levels. Socio-demographic factors, in line with previous studies, were consistently associated with the prevalence of dyslipidaemia [27, 29, 33]. Multivariate analysis in this study also showed that a married status was an independent risk factor for a high TG level; however, female sex was inversely related with the prevalence of the low HDL-C and high TG levels, and a high monthly income was inversely associated with the prevalence of a high TC and low HDL-C level.

Regarding working conditions, we found that underground front-line workers had the lowest prevalence of each kind of dyslipidaemia, and workers who did intense physical work had the lowest prevalence of dyslipidaemia, because the former undertake work of a higher labour intensity. Results of multivariate logistic regression analysis showed that those who did light physical and mental work were inclined to suffer high LDL-C and TG levels and a low HDL-C level than those who did intense physical work. Furthermore, in univariate logistic regression analysis, compared to underground front-line workers, ground workers or office workers and underground auxiliary workers, who frequently but not continuously work under the coal mine, had higher ORs for the prevalence of all dyslipidaemia components; however, multivariate analysis did not confirm these relationships. Results of multivariable logistic regression analysis in this study showed that the extended length of service was an independent risk factor for high TC and high LDL-C levels. Contrary to the expected results, 
participants working inside the coal mine did not show a high prevalence of dyslipidaemia, possibly because of the healthy worker effect and the underground front-line workers may be younger, stronger, and in good health.

With regard to health behaviours, smoking is a main health issue in China; the prevalence of smoking was $57.69 \%$ in our study. Results of multivariate logistic regression analysis also demonstrated that smoking status was associated with high TC levels. With regard to the smoking index, a positive association was shown between a smoking index and high LDL-C levels. Drinking is also a main health issue in China; the prevalence of drinking was $41.49 \%$ in our study. There was an inverse relationship between drinking status and low HDL-C levels in our study, which was in line with the findings of previous research studies [42, 43], and the trend was the opposite for a high TG level. Regarding alcohol consumption per day, an inverse relationship found for low HDL-C levels, although a positive relationship was noted for the prevalence of high TC and high TG levels.

Regarding the health condition, metabolic disturbances, including pathoglycaemia, hypertension, overweight/obesity, abdominal obesity, and dyslipidaemia, occur almost simultaneous with each other and are intensively related to subsequent CVD; the most common underlying mechanism is insulin resistance [44]. Hypertension and diabetes have been reported as risk factors for dyslipidaemia [38, 45-47]. In our study, the prevalence rate of hypertension was as high as $31.38 \%$, and that of IFG/ DM was $14.0 \%$. The increase of dyslipidaemia could have contributed to the high prevalence of hypertension and diabetes among our subjects. Results of multivariate logistic regression analysis showed that participants with elevated fasting glucose levels (IFG/DM) were positively related with all types of dyslipidaemia components; furthermore, a high DBP was a risk factor for high TC levels, high LDL-C levels, and high TG levels. These results proposed that the factors causing dyslipidaemia and the outcomes of dyslipidaemia are similar among people of different ethnicities. Thus, the rising prevalence of dyslipidaemia in China could cause analogous cardio-cerebralvascular outcomes as it did in Western countries [29].

The findings of this study are in line with several previous studies $[38,45,46,48-50]$ that demonstrated that the prevalence of dyslipidaemia rises with an increase in the BMI; additionally, we found that all types of dyslipidaemia were associated with the accumulation of adipose tissue. The abnormal blood lipid panel in overweight and obese people is probably caused by insulin resistance [44]. In China, 3.8\% of men and $5.0 \%$ of women were obese in 2013 [51], but this proportion was almost $20 \%$ in some cities [52]. The respective prevalence rates of overweight and obesity were 39.00 and $17.55 \%$ among coal miners in our study; these values are higher than the Chinese national average values. On the basis of our study's data, we interpreted that obesity is at a high prevalence among coal miners, and it will undoubtedly affect the prevalence of dyslipidaemia. Therefore, obesity in this professional group needs to be noticed. In our research, we found that the prevalence of abdominal obesity among coal miners in China was $13.50 \%$. Other researchers have observed associations between dyslipidaemia and abdominal obesity [43, 53], and our study found that a large WC and hypso-WHR were risk factors for low HDL-C levels and high TG levels. In summary, dyslipidaemia, particularly high TG is a very common and important health problem among Chinese coal miners. Demographic characteristics (advanced age, male sex, marital status, and monthly family income); working characteristics (working type and length of service); lifestyles (smoking, smoking index, drinking status, and alcohol consumption per day); and health conditions (elevated fasting glucose, hypertension, obesity, and abdominal obesity) were closely related to dyslipidaemia. Effective occupational health education must be provided and urgent occupational protective measures must be taken to control the epidemic of dyslipidaemia among coal mine occupational groups.

Several limitations may exist in our study. First, as this was a cross-sectional study, the results are prone to be affected by the recall bias and unmeasured confounding factors. Second, other risk factors (e.g., environmental air pollutants, dietary intake, and other health conditions) were not considered. Finally, this was a crosssectional study, so no causal relationships could be precisely delineated.

\section{Conclusions}

Our current study provides dependable and present epidemic characteristics on dyslipidaemia among Chinese coal miners. Dyslipidaemia, especially high TG levels, is a very prevalent and major health issue among Chinese coal miners.

\section{Abbreviations \\ BMI: Body mass index; CNHS: Chinese National Nutrition and Health Survey; CVD: Cardiovascular disease; DBP: Diastolic blood pressure; DM: Diabetes mellitus; FBG: Fasting blood glucose; HDL-C: High-density lipoprotein cholesterol; IFG: Impaired fasting glucose; LDL-C: Low-density lipoprotein cholesterol; NFG: Normal fasting glucose; OR: Odds ratio; SBP: Systolic blood pressure; TC: Total cholesterol; TG: Triglyceride; WC: Waist circumference; WHR: Waist-hip ratio}

\section{Acknowledgments}

Thanks for the support of Graduate Student Innovation Center in Shanxi Province of China and the assistance of all interviewers and subjects who participated in our study.

\section{Funding}

The study was supported by grants from the National Natural Science Foundation of China (81473073). The funding source had no role in the study design, data collection, data analysis, data interpretation, or writing of the article. 


\section{Availability of data and materials}

The datasets used and analysed during the current study available from the corresponding author on reasonable request.

\section{Authors' contributions}

$\mathrm{JH}, \mathrm{CS}, \mathrm{NQ}$ and TW made substantial contributions to conception and design, and acquisition of data. RT, HW, HZ and YS analyzed the data. YF was a major contributor in writing the manuscript. All authors read and approved the final manuscript.

\section{Ethics approval and consent to participate}

This study was approved by the ethics committee of Shanxi Medical University (ethical application reference: HX201201). Written consent was obtained from all participants.

\section{Consent for publication}

Not applicable

\section{Competing interests}

The authors declare that they have no competing interests.

\section{Publisher's Note}

Springer Nature remains neutral with regard to jurisdictional claims in published maps and institutional affiliations.

\section{Author details}

'Department of Environmental Health, School of Public Health, Shanxi Medical University, 56 Xinjiannanlu Street, TaiYuan, Shanxi 030001, China. ${ }^{2}$ Department of Surgery, General Hospital of Datong Coal Mining Group, DaTong, Shanxi, China. ${ }^{3}$ Department of Health Statistics, School of Public Health, Shanxi Medical University, TaiYuan, Shanxi, China. ${ }^{4}$ Institute for Bacteria disease prevention and control \& disinfection, Hebei province center for disease control and prevention, Shiliazhuang, Hebei, China.

Received: 18 December 2016 Accepted: 14 August 2017

Published online: 23 August 2017

\section{References}

1. Laslett LJ, Alagona P Jr, Clark BA 3rd, Drozda JP Jr, Saldivar F, Wilson SR, Poe C, Hart M. The worldwide environment of cardiovascular disease: prevalence, diagnosis, therapy, and policy issues: a report from the American College of Cardiology. J Am Coll Cardiol. 2012;60:S1-49.

2. Wilson PW, D'Agostino RB, Levy D, Belanger AM, Silbershatz H, Kannel WB. Prediction of coronary heart disease using risk factor categories. Circulation. 1998:97:1837-47.

3. Janus ED, Tideman PA, Dunbar JA, Kilkkinen A, Bunker SJ, Philpot B, Tirimacco R, Mc Namara K, Heistaro S, Laatikainen T. Dyslipidaemia in rural Australia: prevalence, awareness, and adherence to treatment guidelines in the greater green triangle risk factor study. Med J Aust. 2010;192:127-32.

4. Goff DC Jr, Bertoni AG, Kramer H, Bonds D, Blumenthal RS, Tsai MY, Psaty BM. Dyslipidemia prevalence, treatment, and control in the multi-ethnic study of atherosclerosis (MESA): gender, ethnicity, and coronary artery calcium. Circulation. 2006;113:647-56.

5. Grundy SM, Cleeman Jl, Merz CN, Brewer HB Jr, Clark LT, Hunninghake DB, Pasternak RC, Smith SC Jr, Stone NJ. Coordinating Committee of the National Cholesterol Education P. Implications of recent clinical trials for the National Cholesterol Education Program Adult Treatment Panel III guidelines. J Am Coll Cardiol. 2004:44:720-32.

6. Enterline PE. A review of mortality data for American coal miners. Ann N Y Acad Sci. 1972;200:260-72

7. Liu L, Wen F, Xu X, Wang L. Effective resources for improving mental health among Chinese underground coal miners: perceived organizational support and psychological capital. J Occup Health. 2015;57:58-68.

8. Davies HW, Teschke K, Kennedy SM, Hodgson MR, Hertzman C, Demers PA. Occupational exposure to noise and mortality from acute myocardial infarction. Epidemiology. 2005;16:25-32.

9. Bjor B, Burstrom L, Eriksson K, Jonsson H, Nathanaelsson L, Nilsson T. Mortality from myocardial infarction in relation to exposure to vibration and dust among a cohort of iron-ore miners in Sweden. Occup Environ Med. 2010;67:154-8.
10. Dominici F, Peng RD, Bell ML, Pham L, McDermott A, Zeger SL, Samet JM. Fine particulate air pollution and hospital admission for cardiovascular and respiratory diseases. JAMA. 2006;295:1127-34.

11. Rodriguez-Fernandez R, Rahajeng E, Viliani F, Kushadiwijaya H, Amiya RM, Bangs MJ. Non-communicable disease risk factor patterns among mining industry workers in Papua, Indonesia: longitudinal findings from the cardiovascular outcomes in a Papuan population and estimation of risk (COPPER) study. Occup Environ Med. 2015;72:728-35.

12. Oliveira A, Cacodcar J, Motghare DD. Morbidity among iron ore mine workers in Goa. Indian J Public Health. 2014;58:57-60.

13. Conklin DJ, Barski OA, Lesgards JF, Juvan P, Rezen T, Rozman D, Prough RA, Vladykovskaya E, Liu S, Srivastava S, Bhatnagar A. Acrolein consumption induces systemic dyslipidemia and lipoprotein modification. Toxicol Appl Pharmacol. 2010;243:1-12.

14. Fomenko DV, Gorokhova LG, Panev NI, Kazitskaia AS, Bondarev Ol. Clinical and experimental studies of metabolic response to chronic exposure to coal dust. Med Tr Prom Ekol. 2011;(2):15-21.

15. Landen DD, Wassell JT, McWilliams L, Patel A. Coal dust exposure and mortality from ischemic heart disease among a cohort of U.S. coal miners. Am J Ind Med. 2011;54:727-33.

16. Mincheva L, Khadzhiolova I. An occupational physiology study at the Asarel mining and milling works-screening for risk factors of the cardiovascular system in workers in an open-pit mine. Probl Khig. 1995;20:47-59.

17. Haskell WL. Cardiovascular disease prevention and lifestyle interventions: effectiveness and efficacy. J Cardiovasc Nurs. 2003;18:245-55.

18. Costello J, Ortmeyer CE, Morgan WK. Mortality from heart disease in coal miners. Chest. 1975;67:417-21.

19. Vankhanen W. Characteristics of lipid metabolism in deep mine workers and the ways of its alimentary correction. Vopr Pitan. 1992;(1):26-31.

20. Zhonghua Xin Xue Guan Bing Za Zhi. Joint committee issued Chinese guideline for the management of dyslipidemia in a. [2016 Chinese guideline for the management of dyslipidemia in adults]. 2016:44:833-53.

21. Chen C, Lu FC. Department of Disease Control Ministry of health PRC. The guidelines for prevention and control of overweight and obesity in Chinese adults. Biomed Environ Sci. 2004;17(Suppl):1-36.

22. World Health Organization. Waist Circumference and Waist-Hip Ratio: Report of a WHO Expert Consultation. 2008. http://apps.who.int/iris/bitstream/10665/ 44583/1/9789241501491_eng.pdf. Accessed 8-11 December 2008.

23. American DA. Diagnosis and classification of diabetes mellitus. Diabetes Care. 2008:31(Suppl 1):S55-60.

24. James PA, Oparil S, Carter BL, Cushman WC, Dennison-Himmelfarb C, Handler J, Lackland DT, LeFevre ML, MacKenzie TD, Ogedegbe O, et al. 2014 evidence-based guideline for the management of high blood pressure in adults: report from the panel members appointed to the eighth joint National Committee (JNC 8). JAMA. 2014;311:507-20.

25. Perk J, De Backer G, Gohlke H, Graham I, Reiner Z, Verschuren WM, Albus C, Benlian P, Boysen G, Cifkova R, et al. European guidelines on cardiovascular disease prevention in clinical practice (version 2012). The fifth joint task force of the European Society of Cardiology and other societies on cardiovascular disease prevention in clinical practice (constituted by representatives of nine societies and by invited experts). G Ital Cardiol (Rome). 2013;14:328-92

26. Mortality GBD. Causes of death C. Global, regional, and national age-sex specific all-cause and cause-specific mortality for 240 causes of death, 1990-2013: a systematic analysis for the global burden of disease study 2013. Lancet. 2015:385:117-71.

27. Ni WQ, Liu XL, Zhuo ZP, Yuan XL, Song JP, Chi HS, Xu J. Serum lipids and associated factors of dyslipidemia in the adult population in Shenzhen. Lipids Health Dis. 2015;14:71.

28. Zhao WH, Zhang J, Zhai Y, You Y, Man QQ, Wang CR, Li H, Li Y, Yang XG. Blood lipid profile and prevalence of dyslipidemia in Chinese adults. Biomed Environ Sci. 2007;20:329-35.

29. Wang $S, X u L$, Jonas JB, You QS, Wang YX, Yang $H$. Prevalence and associated factors of dyslipidemia in the adult Chinese population. PLoS One 2011:6:e17326.

30. Ruixing Y, Qiming F, Dezhai Y, Shuquan L, Weixiong L, Shangling P, Hai W Yongzhong $Y$, Feng $H$, Shuming $Q$. Comparison of demography, diet, lifestyle, and serum lipid levels between the Guangxi Bai Ku Yao and Han populations. J Lipid Res. 2007:48:2673-81.

31. Zhonghua Xin Xue Guan Bing Za Zhi. Joint Committee for Developing Chinese guidelines on $\mathrm{P}$, Treatment of Dyslipidemia in A. [Chinese guidelines on prevention and treatment of dyslipidemia in adults]. 2007;35:390-419. 
32. Yang W, Xiao J, Yang Z, Ji L, Jia W, Weng J, Lu J, Shan Z, Liu J, Tian H, et al. Serum lipids and lipoproteins in Chinese men and women. Circulation. 2012;125:2212-21.

33. Huang Y, Gao L, Xie X, Tan SC. Epidemiology of dyslipidemia in Chinese adults: meta-analysis of prevalence, awareness, treatment, and control. Popul Health Metr. 2014;12:28.

34. Zhang FL, Xing YQ, Wu YH, Liu HY, Luo Y, Sun MS, Guo ZN, Yang Y. The prevalence, awareness, treatment, and control of dyslipidemia in northeast China: a population-based cross-sectional survey. Lipids Health Dis. 2017;16:61.

35. Li LM, Rao KQ, Kong LZ, Yao CH, Xiang HD, Zhai FY, Ma GS, Yang XG, Technical working Group of China National N, health S. [a description on the Chinese national nutrition and health survey in 2002]. Zhonghua Liu Xing Bing Xue Za Zhi. 2005;26:478-84

36. Li Z, Yang R, Xu G, Xia T. Serum lipid concentrations and prevalence of dyslipidemia in a large professional population in Beijing. Clin Chem. 2005;51:144-50.

37. Zhou B, Rao X, Dennis BH, Li Y, Zhuo Q, Folsom AR, Yang J, Li Y, Stamler J, Cao T, et al. The relationship between dietary factors and serum lipids in Chinese urban and rural populations of Beijing and Guangzhou. PRC-USA cardiovascular and cardiopulmonary research group. Int J Epidemiol. 1995;24:528-34.

38. Bayram F, Kocer D, Gundogan K, Kaya A, Demir O, Coskun R, Sabuncu T, Karaman A, Cesur M, Rizzo M, et al. Prevalence of dyslipidemia and associated risk factors in Turkish adults. J Clin Lipidol. 2014;8:206-16.

39. Johnson CL, Rifkind BM, Sempos CT, Carroll MD, Bachorik PS, Briefel RR, Gordon DJ, Burt VL, Brown CD, Lippel K, et al. Declining serum total cholesterol levels among US adults. The National Health and nutrition examination surveys. JAMA. 1993;269:3002-8.

40. Moran A, Gu D, Zhao D, Coxson P, Wang YC, Chen CS, Liu J, Cheng J, Bibbins-Domingo K, Shen YM, et al. Future cardiovascular disease in china: markov model and risk factor scenario projections from the coronary heart disease policy model-china. Circ Cardiovasc Qual Outcomes. 2010;3:243-52.

41. Wu JY, Duan XY, Li L, Dai F, Li YY, Li XJ, Fan JG. Dyslipidemia in Shanghai. China Prev Med. 2010;51:412-5.

42. Sun GZ, Li Z, Guo L, Zhou Y, Yang HM, Sun YX. High prevalence of dyslipidemia and associated risk factors among rural Chinese adults. Lipids Health Dis. 2014;13:189.

43. Erem C, Hacihasanoglu A, Deger O, Kocak M, Topbas M. Prevalence of dyslipidemia and associated risk factors among Turkish adults: Trabzon lipid study. Endocrine. 2008;34:36-51.

44. Houston MC, Basile J, Bestermann WH, Egan B, Lackland D, Hawkins RG, Moore MA, Reed J, Rogers P, Wise D, Ferrario CM. Addressing the global cardiovascular risk of hypertension, dyslipidemia, and insulin resistance in the southeastern United States. Am J Med Sci. 2005;329:276-91.

45. Sharma U, Kishore J, Garg A, Anand T, Chakraborty M, Lali P. Dyslipidemia and associated risk factors in a resettlement colony of Delhi. J Clin Lipidol. 2013;7:653-60

46. Mirrakhimov EM, Kerimkulova AS, Lunegova OS, Mirrakhimov AE, Nabiev MP, Neronova KV, Bayramukova AA, Alibaeva NT, Satarov N. The association of leptin with dyslipidemia, arterial hypertension and obesity in Kyrgyz (central Asian nation) population. BMC Res Notes. 2014;7:411.

47. Haffner SM. Management of dyslipidemia in adults with diabetes. Diabetes Care. 1998;21:160-78.

48. Shen Z, Munker S, Wang C, Xu L, Ye H, Chen H, Xu G, Zhang H, Chen L, Yu C, Li Y. Association between alcohol intake, overweight, and serum lipid levels and the risk analysis associated with the development of dyslipidemia. J Clin Lipidol. 2014;8:273-8.

49. Calle EE, Thun MJ, Petrelli JM, Rodriguez C, Heath CW Jr. Body-mass index and mortality in a prospective cohort of U.S. adults. N Engl J Med. 1999;341:1097-105.

50. Hubert HB, Feinleib M, McNamara PM, Castelli WP. Obesity as an independent risk factor for cardiovascular disease: a 26-year follow-up of participants in the Framingham heart study. Circulation. 1983;67:968-77.

51. Ng M, Fleming T, Robinson M, Thomson B, Graetz N, Margono C, Mullany EC, Biryukov S, Abbafati C, Abera SF, et al. Global, regional, and national prevalence of overweight and obesity in children and adults during 19802013: a systematic analysis for the global burden of disease study 2013. Lancet. 2014;384:766-81.

52. World Health Organization. Obesity and overweight. 2003. http://www.who. int/dietphysicalactivity/media/en/gsfs_obesity.pdf. Accessed 2003.

53. Villegas R, Kearney PM, Perry IJ. The cumulative effect of core lifestyle behaviours on the prevalence of hypertension and dyslipidemia. BMC Public Health. 2008:8:210.

\section{Submit your next manuscript to BioMed Central and we will help you at every step:}

- We accept pre-submission inquiries

- Our selector tool helps you to find the most relevant journal

- We provide round the clock customer support

- Convenient online submission

- Thorough peer review

- Inclusion in PubMed and all major indexing services

- Maximum visibility for your research

Submit your manuscript at www.biomedcentral.com/submit
C Biomed Central 